\title{
Analisis Beban Kerja Fisiologi Pada Proses Produksi Pembuatan Rumah Boneka Dengan Pekerja Penyandang Disabilitas
}

\author{
TIARA \\ SURYA PERDANA
}

Program Studi Teknik Industri, Universitas Indraprasta PGRI

Jl. Nangka No.. 58 C Tanjung Barat, Jagakarrsa, Jakarta Selaran

tiaramardi.04@gmail.com, suryaperdana.st.mm@gmail.com

\begin{abstract}
PT RB is a UMKM company that manufactures wooden doll houses. This study aims to determine the physiological workload on each operator. this research uses quantitative methods through work physiology approach, the beginning of the study is carried out the calculation of the pulse then the calculation of the energy consumption of each operator is carried out. The next step is to analyze the results of the calculation of energy consumption to find out which work station system has the highest and lowest energy consumption operators. The primary data used in this study include data on body metabolism measurement to assess workload. The Primary data used in this study were obtained from: 10 pulses on doll house production workers to 8 operators with 6 work stations. The greatest energy consumption experienced by the operator at the sanding work station $(41 \mathrm{Kcal} / \mathrm{hour})$. While the lowest value is found in the pattern making work station (2 Kcal/hour). This work is classified as light workload because it is smaller than 100-200Kcal / hour.
\end{abstract}

Key words: Physiology Workload, Doll House, Disability

\begin{abstract}
Abstrak. PT RB merupakan perusahaan UMKM yang memproduksi rumah boneka berbahan dasar kayu. Penelitian ini bertujuan untuk mengetahui beban kerja fisiologi pada masing-masing operator. Penelitian ini menggunakan metode kuantitatif melalui pendekatan fisiologi kerja, awal penelitian dilakukan perhitungan denyut nadi selanjutnya dilakukan perhitungan konsumsi energi masing-masing operator. Langkah selanjutnya dilakukan analisa hasil perhitungan konsumsi energi untuk mengetahui stasiun kerja yang memiliki operator dengan konsumsi energi tertinggi dan terendah. Adapun data Primer yang digunakan dalam penelitian ini diperoleh dari: 10 denyut nadi pada pekerja produksi rumah boneka kepada 8 operator dengan 6 stasiun kerja. Konsumsi energi terbesar dialami oleh operator pada stasiun kerja pengamplasan $(41 \mathrm{Kkal} / \mathrm{jam})$. Sedangkan nilai yang paling rendah terdapat di stasiun kerja pembuatan pola (2 Kkal/jam). Pekerjaan ini tergolong kedalam beban kerja ringan dikarenakan lebih kecil dari 100$200 \mathrm{Kkal} / \mathrm{jam}$.
\end{abstract}

Kata Kunci: Beban Kerja Fisiologi, Rumah Boneka, Disabilitas

\section{PENDAHULUAN}

PT RB merupakan perusahaan UMKM yang memproduksi rumah boneka berbahan dasar kayu. Proses produksi yang dilakukan di PT RB masih berjalan secara sederhana dengan pengerjaan secara manual. Proses produksi kebanyakan dilakukan 
tanpa meja, operator bekerja dengan posisi berjongkok atau duduk di lantai. Di PT RB terdapat 4 orang operator yang memiliki keterbatasan fisik dan harus bekerja menggunakan kursi roda. Posisi kerja seluruh operator dilakukan dengan kondisi jongkok, duduk di lantai dan duduk di kursi roda tanpa meja akan mengurangi kenyamanan operator dalam bekerja, hal tersebut dapat berpotensi menimbulkan penyakit bila terus dibiarkan dalam jangka waktu yang lama. Kegiatan produksi di PT RB dilakukan sekitar 8 jam/hari. Aktivitas material handling dilakukan secara manual. Semua akivitas operator tersebut mengakibatkan kelelahan dengan tingkat denyut jantung yang tinggi. Operator yang mengalami kelelahan secara fisiologi (fisik) dapat menyebabkan penurunan pada produksi, sehingga perlu dilakukan pengukuran beban kerja secara fisiologi dan analisis terhadap proses produksi perusahaan.

Beban kerja merupakan suatu perbandingan antara kapasitas atau kemampuan pekerja/operator dengan tuntutan pekerjaan yang harus dihadapinya. Beban kerja manusia bersifat fisiologis dan psikologis, masing-masing memiliki tingkat pembebanan yang berbeda-beda (Annisa, 2017). Beban kerja operator yang melebihi batas kemampuannya akan menyebabkan kelelahan bahkan dapat menyebabkan cedera, sedangkan beban kerja operator yang terlalu ringan akan menyebabkan kebosanan atau kejenuhan operator terhadap pekerjaannya. Beban kerja yang diberikan kepada operator sebaiknya adalah seimbang dengan kemampuan operator (Mutia, 2014).

Analisis beban kerja dapat digunakan untuk menentukan kebutuhan pekerja, dalam analisis ergonomi, dalam analisis Keselamatan dan Kesehatan Kerja (K3) hingga dalam perencanaan penggajian. Perhitungan beban kerja terdiri dari tiga aspek, yaitu (Puteri, 2017):

1. Aspek Fisik, merupakan perhitungan beban kerja berdasarkan kriteria fisik manusia.

2. Aspek Mental, merupakan perhitungan beban kerja dengan mempertimbangkan aspek mental.

3. Penggunaan waktu, merupakan perhitungan beban kerja dengan mempertimbangkan pada penggunaan waktu untuk bekerja.

Dalam analisis beban kerja fisiologis pengukuran konsumsi energi operator dapat dilakukan dengan 2 cara yaitu (Magrib, 2011):

1. Konsumsi Energi berdasarkan Konsumsi Oksigen

Konsumsi oksigen merupakan faktor dari proses metabolisme yang berhubungan langsung dengan konsumsi energi. Konsumsi oksigen akan terus berlangsung walaupun seseorang tidak melakukan pekerjaan sekalipun. Untuk itu dalam perhitungan konsumsi energi dibagi dalam beberapa keadaan yaitu konsumsi energi pada saat istirahat (metabolisme basal) dan pada saat bekerja.

2. Konsumsi Energi berdasarkan Denyut Jantung

Dalam kondisi normal atau sedang beristirahat, laju detak jantung manusia berkisar diantara $70 \mathrm{bit} / \mathrm{menit}$. Ketika sedang dalam kondisi bekerja, rata-rata laju detak jantung mengalami kenaikan menjadi sekitar 110 bit/menit.

Pengukuran denyut jantung selama bekerja merupakan suatu metode untuk menilai cardiovasculair strain dengan metode 10 denyut, dimana dengan metode ini dapat dihitung denyut nadi kerja dengan rumus sebagai berikut (Ruslani, 2019): 
Denyut nadi untuk mengestimasi indek beban kerja fisik terdiri dari beberapa jenis yaitu:

1. Denyut Nadi Istirahat (DNI) adalah rerata denyut nadi sebelum pekerjaan dimulai

2. Denyut Nadi Kerja (DNK) adalah rerata denyut nadi selama bekerja

3. Nadi Kerja (NK) adalah selisih antara denyut nadi istirahat dengan denyut nadi kerja.

Dalam penentuan konsumsi energi biasanya digunakan seuatu bentuk hubungan energi dengan kecepatan denyut yaitu sebuah persamaan regresi kuadratis sebagai berikut:

$$
\mathrm{E}=1,80411-0,0229038 x+4,71733 \times 10-4 \times 2
$$

Dimana:

$\mathrm{E} \quad=$ Energi (Kkal/menit)

$\mathrm{x} \quad=$ Kecepatan denyut jantung/nadi (denyut/menit)

Setelah melakukan perhitungan di atas, kita dapat menghitung konsumsi energi dengan menggunakan persamaan:

$$
\mathrm{K}=\mathrm{Et}-\mathrm{Ei}
$$

Dimana:

$\mathrm{K}=$ Konsumsi energi (Kkal/menit)

Et $=$ Pengeluaran energi pada waktu kerja tertentu (Kkal/menit)

Ei $=$ Pengeluaran energi pada waktu sebelum bekerja

Sebagai dasar rekomendasi dari KEPMENAKER No. 51 Tahun 1999 yang menetapkan kategori beban kerja menurut kebutuhan kalori sebagai berikut:

1. Beban Kerja Ringan : $100-200 \mathrm{Kkal} / \mathrm{jam}$

2. Beban Kerja Sedang $:>200-350 \mathrm{Kkal} / \mathrm{jam}$

3. Beban Kerja Berat : $\quad>350-500 \mathrm{Kkal} / \mathrm{jam}$

\section{METODE}

Pada penelitian analisis beban kerja fisiologi produksi rumah boneka ini menggunakan metode, yaitu:

\section{Studi Lapangan (Observasi)}

Metode pengumpulan data dengan mengadakan pengamatan langsung pada obyek yang diteliti. Observasi dilakukan guna mendapatkan data umum perusahaan yang meliputi kondisi umum perusahaan, aktivitas yang dilakukan pekerja di masingmasing stasiun kerja, dan jalannya proses produksi.

\section{Wawancara (Interview)}

Pengumpulan data dengan cara melakukan interview atau tanya jawab dengan narasumber yang terkait untuk penelitian yang dilakukan. Wawancara dilakukan pada pimpinan di bagian pembuatan baju dan sejumlah pekerja di bagian tersebut guna mendapatkan data yang benar-benar jelas.

Data yang diperoleh secara langsung dari tempat yang dijadikan sebagai obyek penelitian. Adapun data primer yang digunakan dalam penelitian ini meliputi data pengukuran metabolisme tubuh untuk menilai beban kerja. Adapun data Primer yang 
digunakan dalam penelitian ini diperoleh dari: 10 denyut nadi pada pekerja produksi rumah boneka kepada 8 operator dengan 6 stasiun kerja.

Pengolahan data awal pada penelitian ini yaitu melakukan perhitungan denyut nadi masing-masing operator. Setelah melakukan perhitungan denyut nadi masingmasing operator selanjutnya melakukan perhitungan konsumsi energi pada masingmasing opertaor dengan stasiun kerja yang berbeda-beda. Perhitungan denyut nadi dan konsumsi energi menggunakan rumus sebagai berikut:

1. Denyut Nadi $($ denyut $/ \mathrm{m})=\frac{10 \text { Denyut }}{\text { Waktu perhitungan }} \times 60$

2. Konsumsi Energi

Waktu perhitungan

$$
\begin{array}{ll}
\mathrm{Et} & =(1,80411-0,0229038 \mathrm{X}+4,71733 \times 10-4(X) 2)) \times 60 \\
\mathrm{Ei} & =(1,80411-0,0229038 \mathrm{X}+4,71733 \times 10-4(X) 2)) \times 60 \\
\mathrm{~K} & =\mathrm{Et}-\mathrm{Ei}
\end{array}
$$

Setelah melakukan pengolahan data menggunakan perhitungan denyut nadi dan perhitungan konsumsi energi pada masing-masing operator, maka langkah selanjutnya adalah melakukan analisa hasil perhitungan konsumsi energi yang tertinggi dan terendah dari semua operator produksi rumah boneka.

\section{HASIL DAN PEMBAHASAN}

Pengumpulan data dilakukan dengan cara mengukur per-10 denyut nadi operator di setiap stasiun kerja pada PT RB. Pengukuran dilakukan selama bekerja dan waktu istirahat. Berikut tabel data denyut nadi sesuai stasiun kerja masing-masing:

Tabel 1. Data Denyut Nadi Sesuai Stasiun Kerja (detik)

\begin{tabular}{lccccc}
\hline STASIUN KERJA & DNI & $\mathbf{5}$ & $\mathbf{1 0}$ & $\mathbf{1 5}$ & $\mathbf{2 0}$ \\
\hline Pembuatan pola & & & & & \\
\hline Sunarto & 10,70 & 8,55 & 8,15 & 7,35 & 7,40 \\
\hline Pemotongan pola & & & & & \\
\hline Karsa & 11,30 & 10,26 & 10,05 & 9,50 & 9,27 \\
\hline Pengamplasan & & & & & \\
\hline Andi & 9,70 & 8,50 & 8,03 & 7,50 & 7,20 \\
\hline Pendempulan & & & & & \\
\hline Didik & 9,26 & 8,60 & 7,30 & 7,02 & 8,15 \\
\hline Perakitan & & & & & \\
\hline Yanto & 11,08 & 10,55 & 9,15 & 8,35 & 8,40 \\
\hline Pengecatan & & & & & \\
\hline Nursa & 10,37 & 9,50 & 9,01 & 8,45 & 8,16 \\
\hline
\end{tabular}

Metode penilaian tidak langsung adalah dengan menghitung denyut nadi selama bekerja. Pengukuran denyut jantung selama bekerja merupakan suatu metode untuk menilai beban kerja dengan metode 10 denyut nadi dimana metode ini dapat dihitung sebagai berikut:

Denyut Nadi (denyut $/ \mathrm{m})=\frac{10 \text { Denyut }}{\text { Waktu perhitungan }} \times 60$ 
Contoh perhitungan denyut nadi istirahat dengan menggunakan metode 10 denyut, contoh untuk salah satu operator pada stasiun kerja pembuatan pola Sunarto :

DNI (detik)

Denyut Nadi (denyut/m)

DNI (denyut/menit)

$$
=\frac{10,70}{\text { Waktu perhitungan }} \times 60
$$$$
=\underline{10 \text { Denyut }} \times 60=56,07 \text { Denyut } / \text { menit }
$$
10,70

Perhitungan denyut nadi kerja dengan menggunakan metode 10 denyut, contoh untuk operator sunarto :

DNK (detik)

$=8,55$

Denyut Nadi (denyut/m)

DNK (denyut/menit)

$$
\frac{10 \text { Denyut }}{\text { Waktu perhitungan }} \times 60
$$

$=10$ Denyut $\times 60=70,17$ Denyut $/$ menit

Setelah dilakukan perhitungan maka diperoleh hasil rekapitulasi seperti pada tabel dibawah ini. Untuk lebih lengkapnya dapat dilihat pada tabel 2

Tabel 2. Rekapitulasi Hasil Perhitungan Denyut Nadi pada produksi rumah boneka 10 Denyut

\begin{tabular}{llccccccc}
\hline No. & Nama & $\begin{array}{c}\text { Umur } \\
\text { (Tahun) }\end{array}$ & $\begin{array}{c}\text { DNI } \\
\text { (Denyut) }\end{array}$ & & \multicolumn{2}{c}{ DNK (Denyut) } & \multicolumn{2}{c}{$\begin{array}{c}\text { Rata-rata } \\
\text { (Denyut) }\end{array}$} \\
\hline & & & & $\mathbf{5}$ & $\mathbf{1 0}$ & $\mathbf{1 5}$ & $\mathbf{2 0}$ & \\
\hline 1 & Sunarto & 35 & 56,07 & 70,17 & 73,62 & 81,63 & 81,08 & 56,62 \\
\hline 2. & Karsa & 37 & 59,10 & 54,48 & 59,70 & 63,16 & 64,72 & 60,51 \\
\hline 3. & Andi & 29 & 61,86 & 70,59 & 74,72 & 80 & 83,33 & 77,16 \\
\hline 4. & Didik & 38 & 64,80 & 64,77 & 82,19 & 85,47 & 73,62 & 76,51 \\
\hline 5. & Yanto & 39 & 54,15 & 56,87 & 65,57 & 71,86 & 71,43 & 66,43 \\
\hline 6. & Nursa & 42 & 57,86 & 63,16 & 66,60 & 71,00 & 73,53 & 68,57 \\
\hline
\end{tabular}

\section{Penilaian Konsumsi Energi}

Setelah melakukan perhitungan 10 denyut nadi, selanjutnya menghitung perhitungan konsumsi energi seperti dibawah ini:

\section{Penilaian Konsumsi Energi Pada Proses Pembuatan Pola}

Konsumsi Energi

$(\mathrm{E})=(1,80411-0,0229038 \mathrm{X}+4,71733 \times 10-4(X) 2)) \times 60$

Operator: Sunarto

$$
\begin{aligned}
\mathrm{Et} & =(1,80411-0,0229038(56,62)+4,71733 \times 10-4(56,62) 2)) \times 60 \\
& =(1,80411-1,30+4,71733 \times 0,32)) \times 60 \\
& =121 \mathrm{Kkal} / \mathrm{jam} \\
\mathrm{Ei} & =(1,80411-0,0229038(56,07)+4,71733 \times 10-4(56,07) 2)) \times 60 \\
& =(1,80411-1,28+4,71733 \times 0,31)) \times 60 \\
& =1,99 \times 60 \\
& =119 \mathrm{Kkal} / \mathrm{jam} \\
\mathrm{K} & =\mathrm{Et}-\mathrm{Ei} \\
& =121 \mathrm{Kkal} / \mathrm{jam}-119 \mathrm{Kkal} / \mathrm{jam} \\
& =2 \mathrm{Kkal} / \mathrm{jam}
\end{aligned}
$$


2. Penilaian Konsumsi Energi Pada Proses Pemotongan Pola Konsumsi Energi

$(\mathrm{E})=(1,80411-0,0229038 \mathrm{X}+4,71733 \times 10-4(X) 2)) \times 60$

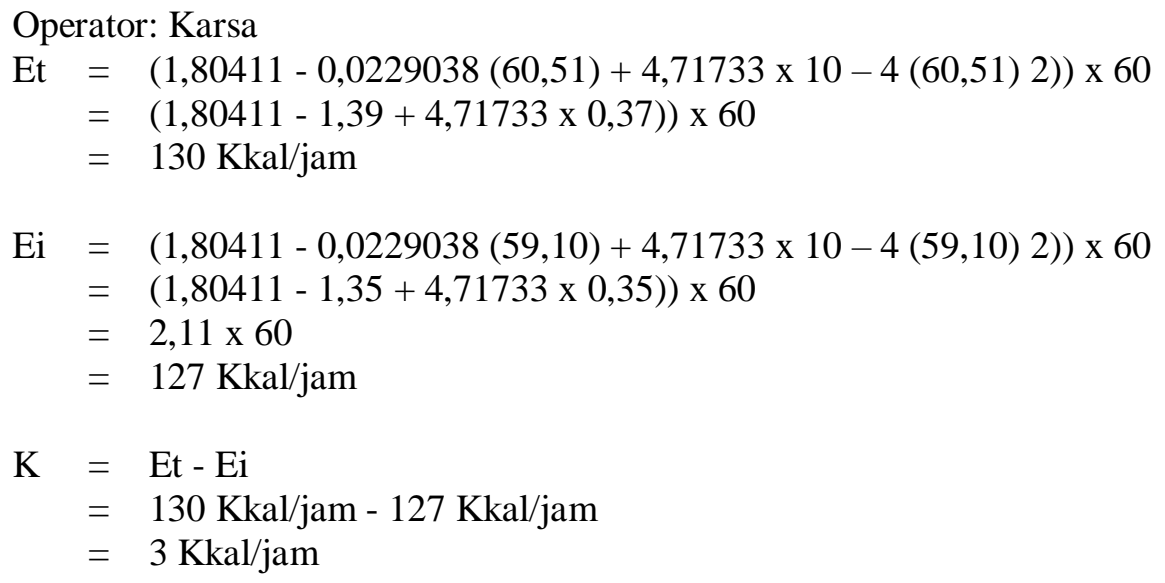

3. Penilaian Konsumsi Energi Pada Proses Pengamplasan Konsumsi Energi

$(\mathrm{E})=(1,80411-0,0229038 \mathrm{X}+4,71733 \times 10-4(X) 2)) \times 60$

Operator: Andi

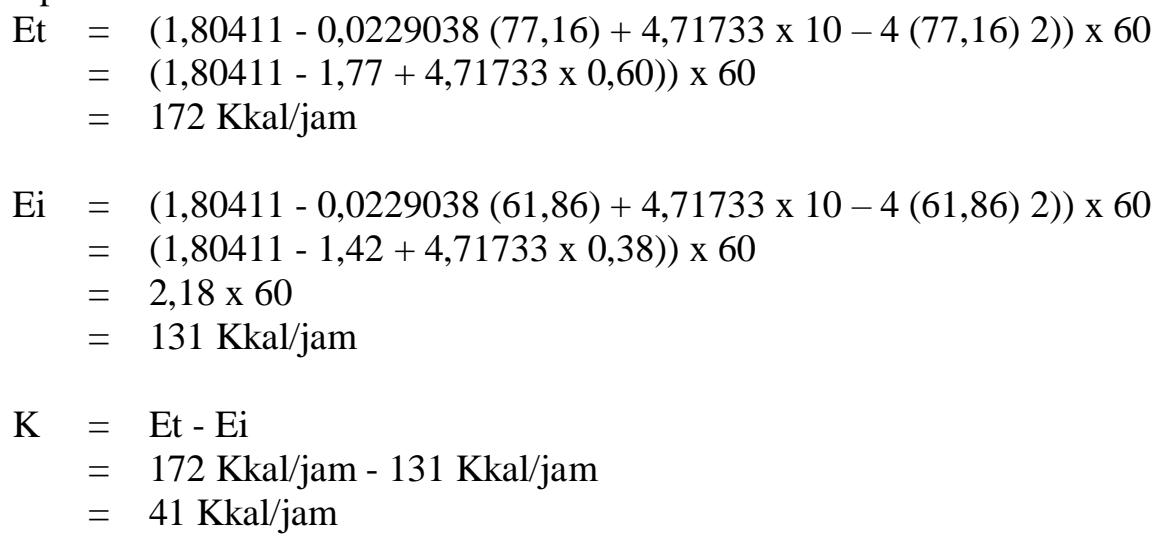

\section{Penilaian Konsumsi Energi Pada Proses Pendempulan} Konsumsi Energi

$(\mathrm{E})=(1,80411-0,0229038 \mathrm{X}+4,71733 \times 10-4(X) 2)) \times 60$

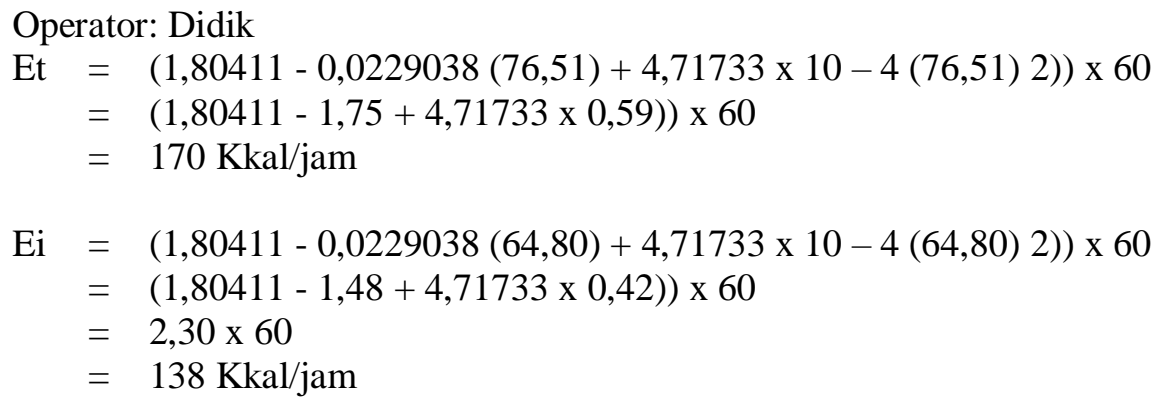




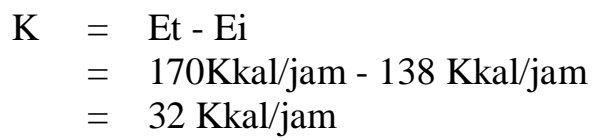

\section{Penilaian Konsumsi Energi Pada Proses Perakitan}

Konsumsi Energi

$(E)=(1,80411-0,0229038 X+4,71733 \times 10-4(X) 2)) \times 60$

Operator: Yanto

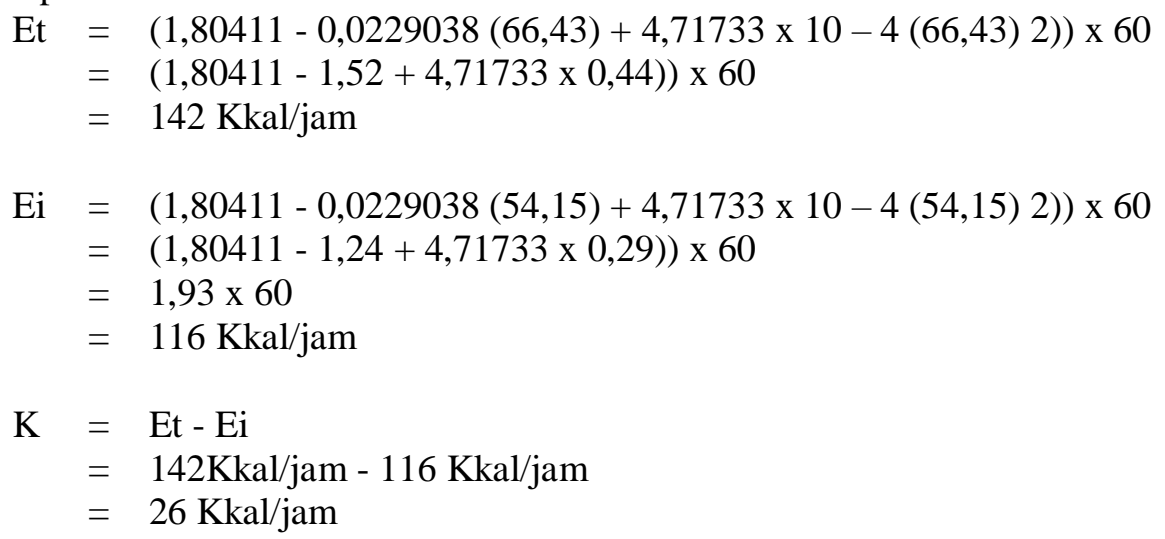

\section{Penilaian Konsumsi Energi Pada Proses Pengecatan}

Konsumsi Energi

$(E)=(1,80411-0,0229038 X+4,71733 \times 10-4(X) 2)) \times 60$

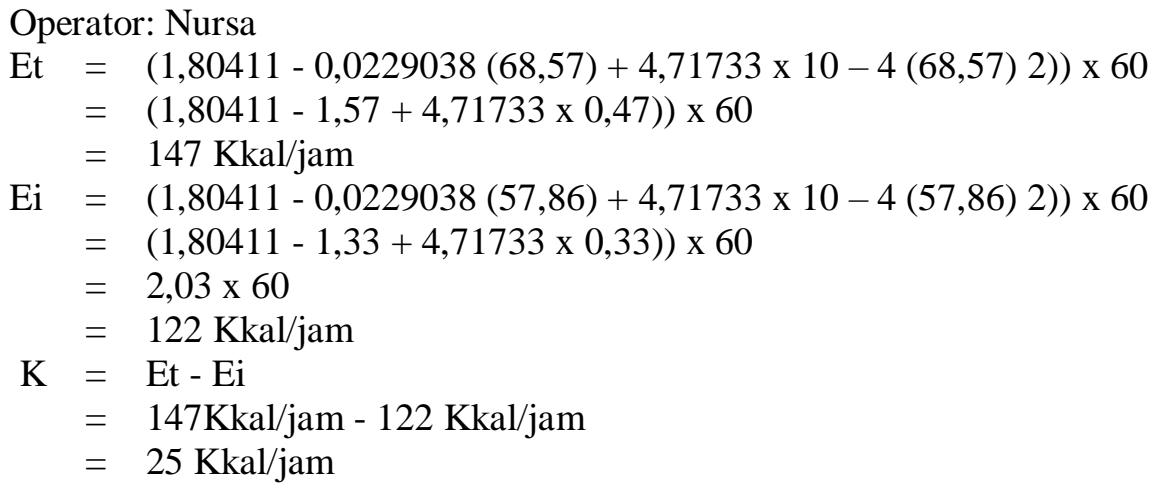

Sehingga dari seluruh pengolahan data di atas dapat diperoleh hasil seperti pada Tabel 3 di bawah ini.

Tabel 3. Hasil Penilaian Konsumsi Energi Pada produksi rumah boneka

\begin{tabular}{cccc}
\hline No. & Operator & Stasiun Kerja & Konsumsi Energi \\
\hline $\mathbf{1}$ & Sunarto & pembuatan pola & $2 \mathrm{Kkal} / \mathrm{jam}$ \\
\hline $\mathbf{2}$ & Karsa & pemotongan pola & $3 \mathrm{Kkal} / \mathrm{jam}$ \\
\hline $\mathbf{3}$ & Andi & proses pengamplasan & $41 \mathrm{Kkal} / \mathrm{jam}$ \\
\hline $\mathbf{4}$ & Didik & proses pendempulan & $32 \mathrm{Kkal} / \mathrm{jam}$ \\
\hline $\mathbf{5}$ & Yanto & proses perakitan & $26 \mathrm{Kkal} / \mathrm{jam}$ \\
\hline $\mathbf{6}$ & Nursa & proses pengecatan & $25 \mathrm{Kkal} / \mathrm{jam}$ \\
\hline
\end{tabular}




\section{Analisa Perhitungan Konsumsi Energi}

Untuk melihat hasil perhitungan konsumsi energi disetiap stasiun kerja dapat dilihat pada tabel 3. Pada Tabel 3 menunjukan perbandingan perhitungan konsumsi energi setiap stasiun kerja. Konsumsi energi terbesar dialami oleh operator pada stasiun kerja pengamplasan (41Kkal/jam). Berdasarkan penjelasan yang telah diuraikan di atas, pada stasiun kerja pengamplasan aktivitas kerja operator adalah mengamplas semua bagian kayu yang tidak rata dan belum halus pada proses pendempulan. Sedangkan nilai yang paling rendah terdapat di stasiun kerja pembuatan pola $(2 \mathrm{Kkal} / \mathrm{jam})$. Pekerjaan ini tergolong kedalam beban kerja ringan dikarenakan lebih kecil dari 100-200Kkal/jam (sesuai dengan kepmenaker No. 51 Tahun 1999).

\section{PENUTUP \\ Simpulan}

Denyut nadi kerja tertinggi pada proses produksi berdasarkan tabel 1 denyut nadi sesuai stasiun kerja (detik) terdapat pada stasiun kerja pemotongan pola dengan denyut nadi rata-rata 11,30 (denyut/menit). Hal ini dapat menyebabkan para pekerja mudah lelah karena aktivitas kerja dari operator adalah memotong triplek yang akan digunakan pada produksi rumah boneka, material yang akan dipotong mulai dari material yang berukuran besar sampai material yang berukuran kecil. Aktivitas ini yang memerlukan tenaga lebih besar sehingga operator tersebut cepat lelah. Nilai denyut nadi kerja terendah terdapat pada stasiun kerja pendempulan dengan denyut nadi rata-rata 9,26 (denyut/menit). Hal ini dikarenakan proses kerja yang hanya mendempul bagian triplek yang tidak rata untuk masuk ke proses produksi sehingga operator tidak mudah lelah dalam melakukan pekerjaan ini. Konsumsi energi terbesar dialami oleh operator pada stasiun kerja pengamplasan $(41 \mathrm{Kkal} / \mathrm{jam})$ beban kerja yang dialami oleh operator cukup berat, maka akan semakin pendek waktu untuk operator bekerja tanpa kelelahan dan gangguan fisiologis yang menyebab salah satu faktor target tidak tercapai.

\section{Saran}

Saran untuk penelitian selanjutnya dianjurkan untuk membahas pengukuran beban kerja yang lain, seperti beban kerja berdasarkan konsumsi oksigen, ventilasi paru, suhu rektal dan beban kerja mental.

\section{DAFTAR PUSTAKA}

Annisa, R. N. dan Farihah, T. 2017. Analisa Beban Kerja Fisik Sebagai Dasar Penentuan Waktu Istirahat yang Optimal (Studi Kasus Di PT. X). Integrated Lab Journal, Vol. 05, No. 01, Hal. 1-12.

Magrib, N. I. D. 2011. Pengukuran Beban Kerja Dengan Metode Fisiologi (Studi Kasus Pada " $X$ " Fitness Center Ambon). MATRIK (Jurnal Manajemen dan Teknik Industri - Produksi), Vol. 11, No. 1, Hal. 50-59.

Mutia, M. 2014. Pengukuran Beban Kerja Fisiologis dan Psikologis Pada Operator Pemetikan Teh dan Operator Produksi Teh Hijau Di PT Mitra Kerinci. Jurnal Optimasi Sistem Industri, Vol. 13 No. 1, Hal. 503-517.

Puteri, R. A. M. dan Sukarna, Z. N. K. 2017. Analisis Beban Kerja Dengan Menggunakan Metode CVL dan NASA-TLX Di PT. ABC. Spektrum Industri, Vol. 15, No. 2, Hal. 121-255.

Ruslani, L. dan Nurfajriah. 2015. Analisis Beban Kerja Fisiologi dan Psikologi Karyawan Pembuatan Baju Di PT Jaba Garmindo Majalengka. Bina Teknika, Vol. 11, No. 2, Hal. 114-123. 